Running head: CALLING AND WORK ENGAGMENT

This is an unedited manuscript published in the

Journal of Counseling Psychology

Please note that the published underwent minor additional editing in style and content.

Cite as:

Hirschi, A. (2012). Callings and work engagement: Moderated mediation model of work meaningfulness, occupational identity, and occupational self-efficacy. J ournal of Counseling Psychology, 59(3), 479-485. doi: 10.1037/a0028949

\title{
Callings and Work Engagement: Moderated Mediation Model of Work Meaningfulness, Occupational Identity, and Occupational Self-Efficacy
}

\author{
Andreas Hirschi \\ University of Lausanne \\ Leuphana University of Lueneburg
}

Correspondence: University of Lausanne, Institute for Psychology, Quartier UNIL-Dorigny, Bâtiment Anthropole; Tel: +41 21692 3289; Fax + +41 2169232 65; CH-1015 Lausanne, Switzerland; E-mail: andreas.hirschi@unil.ch

Acknowledgement. This research was supported by an individual research grant awarded to Andreas Hirschi by the Deutsche Forschungsgemeinschaft (DFG), GZ: HI 1530/2-1

The funding source had no involvement in study design, in the collection, analysis and interpretation of data, in the writing of the report, or in the decision to submit the article for publication. 


\title{
Callings and Work Engagement: Moderated Mediation Model of Work Meaningfulness, Occupational Identity, and Occupational Self-Efficacy
}

\begin{abstract}
Scholarly interest in callings is growing, but our understanding of how and when callings relate to career outcomes is incomplete. The present study investigated the possibility that the relationship of calling to work engagement is mediated by work meaningfulness, occupational identity, and occupational self-efficacy - and that this mediation depends on the degree of perceived person-job fit. I examined a highly educated sample of German employees $(N=529)$ in diverse occupations and found support for two of the three hypothesized mediators - work meaningfulness and occupational identity - after controlling for the relation of core self-evaluations to work engagement. Contrary to expectations, the mediated relations of callings to work engagement were not conditional upon the degree of person-job fit. The findings are considered in terms of the pathways through which callings may relate to work engagement and other career development outcomes.
\end{abstract}

\section{Introduction}

Callings, defined herein in a modern notion (Bunderson \& Thompson, 2009) as a consuming, meaningful passion for a particular career domain (Dobrow \& Tosti-Kharas, 2011) or work that a person perceives as her or his purpose in life (Hall \& Chandler, 2005) address the important question of what makes work and life meaningful (Rosso, Dekas, \& Wrzesniewski, 2010; Steger \& Dik, 2010). A considerable number of university students (Hirschi, 2011; Hunter, Dik, \& Banning, 2010) and employees in various professions (Bunderson \& Thompson, 2009; Duffy, Bott, Allan, Torrey, \& Dik, 2012) report that they regard their work as a calling and callings are likely to affect individual career development and organizations in numerous ways, for example, in terms of increased job satisfaction or organizational commitment (Dobrow \& Tosti-Kharas, 2011; Duffy et al., 2012; Duffy, Dik, \& Steger; Peterson, Park, Hall, \& Seligman, 2009; Wrzesniewski, McCauley, Rozin, \& Schwartz, 1997). Although positive correlations with personal and organizational variables have been demonstrated, theoretical and empirical attempts to explain the influence of callings have been limited (Cardador, Dane, \& Pratt, 2011; Duffy et al.; Steger, Pickering, Shin, \& Dik, 2010). The present study evaluates a model which suggests that the influence of callings on work engagement is mediated by work meaningfulness, occupational identity, and occupational self-efficacy and is conditional upon the degree of perceived person-job (P-J) fit, controlling for a person's core self-evaluations (CSE).

\section{Calling and Work Engagement}

Within the present study, I focus on work engagement as a positive personal and organizational outcome of callings at work, defined as a positive work-related state of fulfillment that is characterized by vigor, dedication, and absorption (Bakker, Schaufeli, 
Leiter, \& Taris, 2008). Work engagement represents a unique and important personal and organizational construct of well-being and thriving at work that is related to, but distinct from, job satisfaction and is significantly related to bottom-line organizational factors such as job performance (Christian, Garza, \& Slaughter, 2011). Theoretically, people with a sense of calling in their careers experience a deep sense of meaning, dedication, and personal involvement in their work (Dik \& Duffy, 2009; Dobrow \& Tosti-Kharas, 2011; Elangovan, Pinder, \& McLean, 2010), which is conceptually related to work engagement. In contrast to work engagement, callings also entail a deep-seated passion toward work and a sense of fulfilling one's life purpose in work (Bunderson \& Thompson, 2009; Dobrow \& Tosti-Kharas, 2011). In an empirical investigation among managers, Dobrow and Tosti-Kharas (2011) confirmed that the two constructs are significantly correlated but empirically distinct.

\section{Mediation of Calling-Work Engagement Relations}

Despite the fact that positive correlations have been established with different personal and organizational outcomes, research addressing the reasons for these relationships remains underdeveloped. Previous research established career commitment, meaningful work, organizational instrumentality, occupational identification, and moral duty as mediators that link calling with positive outcomes such as, among others, organizational commitment, withdrawal intentions, or job satisfaction (Bunderson \& Thompson, 2009; Cardador et al., 2011; Duffy et al., 2011). By extending these previous studies and integrating various theoretical propositions, I propose that callings lead to positive personal and organizational outcomes, such as work engagement, because they enhance a sense of work meaningfulness, occupational identity, and occupational self-efficacy.

Work meaningfulness. Work meaningfulness refers to the amount of significance people perceive in their work (Rosso et al., 2010). Calling and work meaningfulness are theoretically distinct because work can be perceived as meaningful due to certain job characteristics (e.g., feedback, task clarity; for a review see Humphrey, Nahrgang, \& Morgeson, 2007) that are independent of whether the work is perceived as one's purpose in life (i.e., a calling). Conceptually, callings should be regarded as an antecedent to work meaningfulness because callings provide a person with a sense of meaning and purpose in their work (Rosso et al., 2010; Wrzesniewski, 2003) and thus enhance the perception of one's work as meaningful. Supporting this assumption is a cross-sectional study by Duffy et al. (2012), which confirmed that the presence of a calling predicted meaningful work. Work meaningfulness is an important predictor of an array of positive personal and organizational outcomes (for quantitative and qualitative reviews see Humphrey et al., 2007; Rosso et al., 2010) and is a major psychological condition for people's engagement in their work (Christian et al., 2011; May, Gilson, \& Harter, 2004). Hence, I expect increased work meaningfulness to be a major reason why callings are related to work engagement.

Hypothesis 1: Stronger presence of a calling relates to more work engagement indirectly through higher work meaningfulness.

Occupational identity. Occupational identity can be defined as the clear perception 
of occupational interests, abilities, goals, and values, and the structure of the meanings that link these self-perceptions to career roles (Ibarra \& Barbulescu, 2010; Vondracek, 1992). As such, it is conceptually distinct from callings because people can experience a sense of occupational identity without necessarily feeling that their work is their purpose in life. However, the two constructs are theoretically related because a calling entails a sense of identification with the domain of the calling and a sense that this domain is a defining component of one's identity (Dik, Duffy, \& Eldridge, 2009; Dobrow \& Tosti-Kharas, 2011; Hall \& Chandler, 2005). Empirical research has confirmed that the presence of callings is positively correlated with vocational and professional identity (Dobrow \& Tosti-Kharas, 2011; Hirschi, 2011) as well as the related constructs of career decidedness (Duffy \& Sedlacek, 2007), job involvement (Dobrow \& Tosti-Kharas, 2011), and career commitment (Duffy et al., 2012). Hence, I propose that one of the major effects of callings is their positive relationship to clarity of occupational identity. Theoretically, occupational identity gives meaning and direction to one's career, increases coping abilities in the face of stress and challenges, and allows an individual to find work that reflects his or her personal strengths, interests, preferences, and goals (Skorikov \& Vondracek, 2011). Empirical research showed that conceptually closely related constructs to occupational identity, such as professional identification (Ashforth, Harrison, \& Corley, 2008), career decidedness and self-clarity (Earl \& Bright, 2007), career commitment (Goulet \& Singh, 2002), and identity achievement (Luyckx, Duriez, Klimstra, \& De Witte, 2010) are related to various positive personal and organizational outcomes, including higher work engagement (Luyckx et al., 2010). Hence, I expect that callings are positively related to work engagement because they enhance a person's sense of occupational identity.

Hypothesis 2: Stronger presence of a calling relates to more work engagement indirectly through higher clarity of occupational identity.

Occupational self-efficacy. This domain-specific assessment of self-efficacy refers to the competence that a person feels concerning his or her ability to successfully fulfill the tasks involved in his or her work (Rigotti, Schyns, \& Mohr, 2008). While conceptually distinct form calling, the two constructs are theoretically related. People with a calling should experience a sense of competence in the domain of their calling (Hall \& Chandler, 2005), that is partially based on experiencing subjective career success (Dobrow \& Tosti- Kharas, 2011). That is, having a sense of calling should, theoretically, lead people to pursue goals and tasks that are consistent with their calling and lead them to invest more effort in the pursuit of those goals and task. This would in turn increase the likelihood of objective success as well as subjective success in terms of satisfaction when goals are achieved and tasks completed. Such perceived objective and subjective success should then promote stronger task-related self-efficacy beliefs (Hall \& Chandler, 2005). Empirical research has confirmed that career self-efficacy is significantly related to callings (Hirschi, 2011), that the presence of a calling is related to self-efficacy in career decision-making among university students (Duffy \& Sedlacek, 2007), and that a calling predicts career self-efficacy among artists and musicians, even several years later (Dobrow \& Tosti-Kharas, 2011). Self-efficacy beliefs are an important 
predictor of various positive personal, organizational, and career outcomes, including career success, job satisfaction, and performance (Betz, 2007; Judge \& Bono, 2001; Judge, Jackson, Shaw, Scott, \& Rich, 2007). These beliefs increase motivation and effort in working toward the attainment of a goal as well as resiliency and persistence in the face of obstacles (Bandura, 1997). Studies on work engagement have demonstrated that self-efficacy beliefs are an important personal resource that predicts greater engagement at work (Bakker et al., 2008). Hence, I assume that occupational self-efficacy mediates the relation of callings on work engagement.

Hypothesis 3: Stronger presence of a calling relates to more work engagement indirectly through stronger occupational self-efficacy.

\section{A Moderated Mediation Hypothesis}

Although researchers have empirically established that callings relate to a variety of career outcomes, less attention has been paid to the conditions of these effects. In the present study, I propose that the degree to which a person is able to find work that provides a good fit with his or her own values, skills, and preferences is a critical moderator. The importance of finding work that provides a good fit is stressed in religious (Schuurman, 2003) and secular (Peterson et al., 2009) notions of calling and is a major component of career counseling generally (Fouad, 2007) and calling-oriented interventions specifically (Dik et al., 2009; Thompson \& Feldman, 2010). Empirical research has confirmed that P-J fit is significantly related to various positive personal and organizational outcomes, such as tenure, satisfaction, and performance (Kristof-Brown, Zimmerman, \& Johnson, 2005). Conversely, callings that cannot be enacted in a particular domain or job (e.g., when an aspiring musician is forced to abandon her career choice and work as an accountant) may lead to personal distress and low satisfaction and engagement at work. A qualitative study by Berg et al. (2010) showed that people report feelings of regret and stress in response to unanswered callings, and a quantitative study by Duffy et al. (2012) suggests that the degree to which employees reported that they were living their calling moderated the relationship between the presence of a calling and job satisfaction.

Hypothesis 4: The indirect relation of calling to work engagement through (a) work meaningfulness, (b) occupational identity, and (c) occupational self- efficacy is conditional on the degree of perceived $P$-J fit, in that the mediation effects are stronger under conditions of high $P-J$ fit.

Controlling for core self-evaluations. As also cautioned by other researchers (Dobrow \& Tosti-Kharas, 2011), one shortcoming of many previous studies investigating the effects of callings on personal and organizational outcomes is that they did not control for relatively stable personal dispositions that might explain the relation between calling and its alleged consequences. For example, empirical studies showed weak to moderate positive correlations between the presence of a calling and CSE (Duffy, Allan, \& Bott, in press; Hirschi, 2011), the basic, fundamental appraisal of one's worthiness, effectiveness, and capability as a person (Judge, Erez, Bono, \& Thoresen, 2003). Research has also shown that 
CSE are related to a number of personal, career, and organizational outcomes, including life satisfaction, career self-efficacy, job satisfaction, and vocational identity (Erez \& Judge, 2001; Hirschi, 2011; Judge, Van Vianen, \& De Pater, 2004). Consequently, I will control for the effects of CSE in the analyses and assume that the proposed hypotheses hold under this condition. This procedure allows making stronger inferences regarding the unique effects of callings that cannot simply be attributed to a common third factor.

\section{Method}

\section{Participants and Procedure}

The sample consisted of university alumni across all available study fields from three universities in northern Germany. Participants were recruited through the alumni newsletters of the universities, which were sent to approximately 4,400 people. No reminders were possible. Participation was approximately $12 \%(N=529)$. The participants were $39.7 \%$ female, age $M=28.97, S D=4.68$, organizational tenure $M=2.16$ years, $S D=$ 2.37. Most had a master's degree (56\%) and $27 \%$ held a bachelor's degree, the other had different degrees or provided no information (8\%). The most frequent fields of work consisted of engineering $(23.4 \%)$, business administration (16.8\%), marketing $(10.2 \%)$, human resources (7.2\%), information technology (7\%), and education (6.8\%). Race/ethnicity was not assessed as this is not a commonly assessed demographic variable in Germany.

\section{Measures}

Bivariate intercorrelations for scores across continuous variables are reported in Table 1, with coefficient alphas reported on the diagonal.

Presence of calling. The degree to which participants reported having a calling in their career was assessed with the German version (Hirschi, 2011) of the two-item ("I have a calling to a particular kind of work"; "I have a good understanding of my calling as it applies to my career") Presence subscale of the Brief Calling Scale (BCS; Dik, Eldridge, Steger, \& Duffy, in press) on a five-point Likert scale, 1 (not at all true of me) to 5 (totally true of me). A recent multitrait-multimethod matrix design validation study (Dik, Eldridge, Steger, \& Duffy, in press) found that the BCS scores correlated positively with scores of other measures of calling and with informants' reports of participants' perceptions of their calling. Empirical studies using this scale reported correlations between the two items between $r=.76$ and .82 and have shown significant relationships with career decision self-efficacy, intrinsic work motivation, religious commitment, and meaning in life (Dik \& Steger, 2008; Duffy \& Sedlacek, 2007; Steger, Pickering, Shin, \& Dik, 2010).

Work meaningfulness. Perceived meaning at work was measured with the five-item scale (e.g., "I have a meaningful job") developed by Bunderson and Thompson (2009), on a five-point Likert scale, 1 (not at all) to 5 (completely). The scale was independently translated into German by two researchers and a consensus was reached regarding the final version. Supporting the scale's concurrent validity, Bunderson and Thompson reported a scale reliability estimate of $\alpha=.89$ and found significant correlations with occupational 
identification, occupational importance, and a neoclassical presence of calling among zookeepers.

Occupational identity. The clarity of personal characteristics and career goals was measured with the seven-item (e.g., "I'm not sure yet which occupations I could perform successfully") German-language adaptation of the Vocational Identity Scale (Holland, Daiger, \& Power, 1980; Jörin, Stoll, Bergmann, \& Eder, 2004) on a five-point Likert scale, 1 (not at all) to 5 (completely). Research with the German language version reported scale reliabilities between $\alpha=.81$ and .89 and suggests that the scale shows significant positive correlations with career decidedness, career planning, and career exploration among adolescents and college students (Hirschi \& Läge, 2007; Jörin, et al., 2004).

Occupational self-efficacy. I assessed the participants' confidence in mastering various tasks in their occupations with the six-item (e.g., "Whatever comes my way in my job, I can usually handle it") short version of the Occupational Self-Efficacy Scale, on a fivepoint Likert scale, 1 (not at all) to 5 (completely), developed and validated by Rigotti, Schyns, and Mohr (2008). The authors of the scale (Rigotti et al., 2008) reported a scale reliability of $\alpha=.84$ and evidence of construct validity among a large group of German employees with significant relationships with job satisfaction, organizational commitment, job performance, and job insecurity.

Work engagement. I applied the German-language, nine-item (e.g., "At my work, I feel that I am bursting with energy") short version of the Utrecht Work Engagement Scale (UWES; Schaufeli, Bakker, \& Salanova, 2006) to assess the amount of vigor, dedication, and absorption at work with a seven-point Likert scale, 0 (never) to 6 (always). The scale has been extensively used in research, supporting its convergent, divergent and predictive validity (e.g., Seppälä, Mauno, Feldt, Hakanen, Kinnunen, Tolvanen,... 2009), for example in relation to job satisfaction, job performance, or turn-over intentions. Scale reliability was reported with Cronbach's alpha ranging between .81 and .92 in other samples (Schaufeli et al. 2006).

Person-environment fit. I used the four-item scale developed by Saks and Ashforth (2002) to measure fit perceptions regarding the participants' job (e.g., "To what extent do your knowledge, skills, and abilities match the requirements of the job?") on a five-point Likert- type scale, 1 (to a very little extent) to 5 (to a very large extent). The scale was independently translated into German by two researchers and a consensus was reached regarding the final version. Supporting the scale's concurrent validity, the authors of the scale (Saks \& Ashforth, 2002) reported a scale reliability of $\alpha=.87$ and significant correlations with job satisfaction, organizational commitment, and intention to quit among university graduates.

Core self-evaluations. CSE were assessed with the 12-item (e.g., "I am confident that I will get the success I deserve in life") German-language version of the CSE scale by Judge et al. (Judge et al., 2003; Stumpp, Muck, Hülsheger, Judge, \& Maier, 2010) on a five-point Likert-type scale, 1 (strongly disagree) to 5 (strongly agree). A large number of studies support the validity of the original scale, including its relationships with job satisfaction, career success, 
and job stress (e.g., Judge, Van Vianen, \& De Pater, 2004). Stumpp et al. (2010) reported scale reliabilities for the German version ranging from $\alpha=.81$ to 87 and supported validity in terms of factorial structure and significant relationships with job and life satisfaction and organizational commitment among samples of German working adults.

\section{Results}

\section{Preliminary Confirmatory Factor Analyses}

I conducted a series of confirmatory factor analyses (CFA) with Mplus to estimate the distinctness of the assessed variables. Preliminary tests showed a significant deviation from multivariate normality, Mardia' $s$ test $b 2 p=2622.34, N(b 2 p)=89.71, p<.001$, and the maximum likelihood parameter estimation with standard errors (MLR) was used for model estimation because this procedure produces parameter estimates that are robust to nonnormality and allows estimating missing values on singe items (Yuan \& Bentler, 2000). The results showed that the hypothesized seven-factor model, distinguishing the presence of calling, person-job fit, work meaningfulness, occupational identity, occupational selfefficacy, work engagement, and CSE, fit the data well on two of four fit indices: $\chi 2(924, N=$ $529)=1842.64 ; p<.001 ;$ CFI (Comparative Fit Index) $=.90, T L I$ (Tucker Lewis Index) = .90, RMSEA (Root Mean Square Error of Approximation) $=.04(90 \% \mathrm{Cl} .04-.05)$, and SRMR (Standardized Root Mean Square Residual) $=.06$. This model provided a significantly better fit (all $p<.001$ ) than a model in which all three mediating variables were combined into one mediating factor; a five-factor model distinguishing factors of P-J fit, CSE, work engagement, and a factor combining calling and the three mediators; three different six-factor models that collapsed calling with each of the three mediators into a single factor; or a one-factor model (i.e., combining all seven variables into one factor). Standardized loadings of the scale items on their respective factors were significant (all $p<.001$ ), ranging from .45 to .92. The correlations among the latent constructs were significant (all $p<.001$ ) and mostly large (median = .54), with a range of .36 to .77 . In sum, despite support for the seven-factor model, the results indicated substantial overlap among most of the constructs.

\section{Multiple Mediation Effects}

To test the hypotheses that the relation of presence of a calling to work engagement is mediated by work meaningfulness, occupational identity, and occupational self- efficacy, I calculated a multiple mediation model with the bootstrapping approach in Mplus, as described by Preacher and Hayes (2008) using 5,000 bootstrapping samples. The effects of CSE were controlled by regressing all other variables in the model onto it. The results in Table 2 show that there was a significant total indirect effect of calling on work engagement, mediated by the proposed variables. The direction of the effects supports the hypotheses that a calling relates to greater work meaningfulness, occupational identity, and occupational selfefficacy, which, in turn, are related to greater work engagement. Moreover, meaningfulness and identity exhibited significant indirect effects, supporting $\mathrm{H} 1$ and $\mathrm{H} 2$, as indicated by significant point estimates and the $95 \%$ bootstrapping confidence intervals $(\mathrm{Cl})$ not including 
zero. However, while the point estimate for self-efficacy was significant, the more reliable bootstrapping $95 \% \mathrm{Cl}$ included zero, indicating a nonsignificant indirect effect and not clearly supporting H3. Contrast tests assessing the specific indirect effects (i.e., the unique abilities of each mediator to account for the relation of calling on work engagement; Preacher \& Hayes, 2008) showed that the mediation through self-efficacy was significantly weaker (both $p<.001$ ) than those of meaningfulness and identity. No difference emerged between the effects of meaningfulness and identity.

\section{Conditional Indirect Effects}

I tested the conditional indirect effects, (i.e., moderated mediation) with Model 8 in the PROCESS bootstrapping approach provided by Hayes (http://www.afhayes.com/spss-sasand-mplus-macros-and-code.html). Conditional indirect effects were assessed at the 10th, 25th, 50th, 75th, and 90th percentiles of P-J fit. The results provided no support for $\mathrm{H} 4$ and indicated no moderation of the indirect effects of calling on work engagement by P-J fit (complete results are available from the author upon request). The indirect effects (point estimates) were significant at all assessed levels of P-J fit for meaning and identity and the $95 \% \mathrm{Cl}$ of the bias-corrected bootstrapping analyses did not contain zero at any level. For selfefficacy, no indirect effects emerged at any of the five assessed levels of P-J fit.

\section{Discussion}

The present work enhances our understanding of how and when callings are positively related to favorable individual and organizational outcomes. Specifically, the results support the theoretical model that callings have positive outcomes because they provide a sense of meaningfulness and identity at work. As suggested by the findings, these factors allow people to more often experience work engagement, or vigor, dedication, and absorption at work. The results confirm the theoretical link between a calling and meaningful work (Dobrow \& TostiKharas, 2011; Duffy et al., 2012; Rosso et al., 2010) and support the theoretical assumption that callings are an important factor in understanding what makes work meaningful (Rosso et al., 2010; Steger \& Dik, 2010; Wrzesniewski, 2003). They also support the notion that callings facilitate identification with the domain of the calling and a sense that this domain is a defining component of one's identity (Dik et al., 2009; Dobrow \& Tosti-Kharas, 2011; Hall \& Chandler, 2005). Future studies are encouraged to include callings as a predictor of meaningful work and identity at work. In contrast, there was less support for the mediating role of occupational self-efficacy. Theoretically, callings should increase a person's subjective career success which in turn enhances the estimated ability in their calling domain (Dobrow \& Tosti-Kharas, 2011; Hall \& Chandler, 2005; Hirschi, 2011). However, this process may require time to develop because it is expected to be partially based on successful work experiences. Because the present sample consisted of young professionals with relatively little work experience, callings may not yet have shown their full potential in relation to self-efficacy, thus limiting their mediating power. For future research, it may be useful to investigate the mediating role of self-efficacy among senior employees. It is also notable that the positive relations of callings with the other assessed variables were evident despite controlling for CSE 
and the present study provides support for the proposition that callings have positive individual and organizational effects that are not explained only by personality traits.

In addition to addressing the potential mediators of callings, the present study examined the conditions under which these mediated relationships between callings and work engagement may occur. Contrary to the assumptions, the indirect effects of callings on work engagement were not conditional on level of P-J fit. This contradicts previous research that examined living a calling as a moderator and found significant moderating effects on job satisfaction (Duffy et al., 2012). It is possible that no conditional effects could be established for the indirect effects in the present study because the study participants showed very high P-J fit on average. The positive bias in the P-J fit measure might be explained by attrition biases: people who are more satisfied with their current work might be more likely to participate in a study of this nature. However, due to processes of attraction-selectionattrition (Schneider, 1995) it is generally unlikely to find a large number of people with low P-J fit perceptions among working samples. Conversely, the notion of living a calling, or working in an job that supports that calling, is more specific than the more general notion of P-J fit. Consequently, the sample of Duffy et al. (2012) showed a larger range, lower relative mean score and higher variance in the living a calling measure compared to the scores obtained in the present sample regarding P-J fit perception. Hence, one explanation for the contradicting results could be that the more specific notion of living a calling seems to show more variance among working samples than more general P-J fit perceptions. It is also possible that people with a sense of calling are more successful in finding work that fits their personal needs and abilities because they are more engaged in their career management (Hirschi, 2011), thus further decreasing the individual differences in P-J fit in relation to presence of calling. In sum, the results suggest that within a given job, a calling can be expected to have positive personal and organizational effects, such as work engagement, and that the consequences of individual differences in P-J fit are negligible.

\section{Limitations}

There are several limitations to consider when interpreting the results of the present study. First, although I sampled a broad category of professions, data were restricted to young professionals. Thus, it is important for future studies to investigate the proposed model within different populations, such as blue-collar or older workers. Second, the cross-sectional selfreport research design does not allow investigating the developmental effects and patterns that link callings with work outcomes and mediators and induces shared method variance, which may have affected the observed relationship among the measures. Third, the mediating role of self-efficacy may have been reduced by the very high correlation between CSE and occupational self-efficacy. Such multicollinearity considerably reduces the unique amount variance shared between self-efficacy and the other variables when CSE is controlled. Fourth, although the assessed constructs were technically distinct, they showed a considerable overlap as indicated by their moderate to high correlations. Future research needs to further establish to what extent calling is a unique construct that has incremental validity above and 
beyond related variables. Related to this point, the CFI and TLI fit indices indicated that the proposed seven-factor model was not optimal and that the measurement model might be further improved. Fifth, although similar to other studies (Duffy et al., 2011), the response rate was low and raises issues of generalizability. Finally, the applied calling measure has received support for construct validity in other studies but it lets participants define their own meaning of calling. While this takes account of the fact that there is no commonly agreed definition of calling in the literature, it means that it is not exactly clear what the participants understood as "calling". Hence, the present study does not allow a clear statement about what is actually meant and measured by "calling". This might specifically be an issue because the notion of calling could differ in the present German context compared to extant U.S. samples.

\section{Counseling Implications}

Based on the results of the current study counselors can, on average, assume that, within a given job, individuals with a sense of calling would have a more positive sense of work engagement. Because the present study uncovered more closely why callings have beneficial outcomes, the results have also implications on how to obtain the benefits typically associated with callings for the large number of clients who do not experience a calling. While other authors focused on helping clients finding their calling (Dik et al., 2009; Dik \& Steger, 2008; Thompson \& Feldman, 2010), a different approach suggested by this study might be to directly enhance clients' sense of work meaningfulness and occupational identity in order increase their positive work experiences, regardless of whether they report a calling or not. For this purpose, counseling approaches that focus on identity construction and meaning-making (e.g., Savickas et al., 2009) seem particularly useful. 


\section{References}

Ashforth, B. E., Harrison, S. H., \& Corley, K. G. (2008). Identification in Organizations: An Examination of Four Fundamental Questions. Journal of Management, 34(3), 325- 374. doi: 10.1177/0149206308316059

Bakker, A. B., Schaufeli, W. B., Leiter, M. P., \& Taris, T. W. (2008). Work engagement: An emerging concept in occupational health psychology. Work \& Stress, 22(3), 187-200.

Bandura, A. (1997). Self-efficacy: The exercise of control. New York; NY: Freeman.

Berg, J. M., Grant, A. M., \& Johnson, V. (2010). When callings are calling: Crafting work and leisure in pursuit of unanswered occupational callings. Organization Science, 21(5), 973-994. doi: 10.1287/orsc.1090.0497

Betz, N. E. (2007). Career Self-Efficacy: Exemplary Recent Research and Emerging Directions. Journal of Career Assessment, 15(4), 403-422. doi: 10.1177/1069072707305759

Bunderson, J. S., \& Thompson, J. A. (2009). The call of the wild: Zookeepers, callings, and the doubleedged sword of deeply meaningful work. Administrative Science Quarterly, 54(1), 32-57. doi: 10.2189/asqu.2009.54.1.32

Cardador, M. T., Dane, E., \& Pratt, M. G. (2011). Linking calling orientations to organizational attachment via organizational instrumentality. Journal of Vocational Behavior, 79(2), 367378. doi: 10.1016/j.jvb.2011.03.009

Christian, M. S., Garza, A. S., \& Slaughter, J. E. (2011). Work engagement: A quantitative review and test of its relations with task and contextual performance. Personnel Psychology, 64(1), 89136. doi: 10.1111/j.1744-6570.2010.01203.x

Dik, B. J., \& Duffy, R. D. (2009). Calling and vocation at work: Definitions and prospects for research and practice. The Counseling Psychologist, 37(3), 424-450. doi: 10.1177/0011000008316430

Dik, B. J., Duffy, R. D., \& Eldridge, B. M. (2009). Calling and vocation in career counseling: Recommendations for promoting meaningful work. Professional Psychology: Research and Practice, 40(6), 625-632. doi: 10.1037/a0015547

Dik, B. J., Eldridge, B. M., Steger, M. F., \& Duffy, R. D. (in press). Development and validation of the Calling and Vocation Questionnaire (CVQ) and Brief Calling Scale (BCS). Journal of Career Assessment.

Dik, B. J., \& Steger, M. F. (2008). Randomized trial of a calling-infused career workshop incorporating counselor self-disclosure. Journal of Vocational Behavior, 73(2), 203- 211. doi: 10.1016/j.jvb.2008.04.001

Dobrow, S. R., \& Tosti-Kharas, J. (2011). Calling: The development of a scale measure. Personnel Psychology, 64(4), 1001-1049. doi: 10.1111/j.1744-6570.2011.01234.x

Duffy, R., Allan, B., \& Bott, E. (in press). Calling and life satisfaction among undergraduate students: Investigating mediators and moderators. Journal of Happiness Studies. doi: 10.1007/s10902011-9274-6

Duffy, R. D., Bott, E. M., Allan, B. A., Torrey, C. L., \& Dik, B. J. (2012). Perceiving a calling, living a calling, and job satisfaction: Testing a moderated, multiple mediator model. Journal of Counseling Psychology, 59(1), 50-59. doi: 10.1037/a0026129

Duffy, R. D., Dik, B. J., \& Steger, M. F. (2011). Calling and work-related outcomes: Career commitment as a mediator. Journal of Vocational Behavior, 78(2), 210-218. doi:10.1016/j.jvb.2010.09.013

Duffy, R. D., \& Sedlacek, W. E. (2007). The presence of and search for a calling: Connections to career development. Journal of Vocational Behavior, 70(3), 590-601. doi: 10.1016/j.jvb.2007.03.007

Earl, J. K., \& Bright, J. E. H. (2007). The relationship between career decision status and important 
work outcomes. Journal of Vocational Behavior, 71(2), 233-246. doi: 10.1016/j.jvb.2007.05.003

Elangovan, A. R., Pinder, C. C., \& McLean, M. (2010). Callings and organizational behavior. Journal of Vocational Behavior, 76(3), 428-440. doi: 10.1016/j.jvb.2009.10.009

Erez, A., \& Judge, T. A. (2001). Relationship of core self-evaluations to goal setting, motivation, and performance. Journal of Applied Psychology, 86(6), 1270-1279. doi: 10.1037/00219010.86.6.1270

Fouad, N. A. (2007). Work and vocational psychology: Theory, research, and applications. Annual Review of Psychology, 58(1), 543-564. doi: 10.1146/annurev.psych.58.110405.085713

Goldman, B. M., \& Kernis, M. H. (2002). The role of authenticity in healthy psychological functioning and subjective well-being. Annals of the American Psychotherapy Assn, 5(6), 18-20.

Goulet, L. R., \& Singh, P. (2002). Career Commitment: A Reexamination and an Extension. Journal of Vocational Behavior, 61(1), 73-91.

Hall, D. T., \& Chandler, D. E. (2005). Psychological success: When the career is a calling. Journal of Organizational Behavior, 26(2), 155-176. doi: 10.1002/job.301

Hirschi, A. (2011). Callings in career: A typological approach to essential and optional components. Journal of Vocational Behavior, 79(1), 60-73. doi: 10.1016/j.jvb.2010.11.002

Hirschi, A., \& Läge, D. (2007). Holland's secondary constructs of vocational interests and career choice readiness of secondary students. Journal of Individual Differences, 28(4), 205-218. doi: 10.1027/1614-0001.28.4.205

Holland, J. L., Daiger, D. C., \& Power, P. G. (1980). My Vocational Situation. Palo Alto, CA: Consulting Psychologists Press.

Humphrey, S. E., Nahrgang, J. D., \& Morgeson, F. P. (2007). Integrating motivational, social, and contextual work design features: A meta-analytic summary and theoretical extension of the work design literature. Journal of Applied Psychology, 92(5), 1332-1356. doi: 10.1037/00219010.92.5.1332

Hunter, I., Dik, B. J., \& Banning, J. H. (2010). College students' perceptions of calling in work and life: A qualitative analysis. Journal of Vocational Behavior, 76(2), 178-186. doi: 10.1016/j.jvb.2009.10.008

Ibarra, H., \& Barbulescu, R. (2010). Identity as narrative: Prevalence, effectiveness, and consequences of narrative identity work in macro work role transitions. Academy of Management Review, 35(1), 135-154.

Jörin, S., Stoll, F., Bergmann, C., \& Eder, D. (2004). Explorix ${ }^{\circledR}$ - das Werkzeug zur Berufswahl und Laufbahnplanung [Explorix - the tool for career choice and career planning]. Berne, Switzerland: Hans Huber.

Judge, T. A., \& Bono, J. E. (2001). Relationship of core self-evaluations traits - self-esteem, generalized self-efficacy, locus of control, and emotional stability - with job satisfaction and job performance: A meta-analysis. Journal of Applied Psychology, 86(1), 80-92. doi: 10.1037//0021-9010.86.1.80

Judge, T. A., Erez, A., Bono, J. E., \& Thoresen, C. J. (2003). The Core Self-Evaluations Scale. Development of a measure. Personnel Psychology, 56(2), 303-331. doi: 10.1111/j.17446570.2003.tb00152.x

Judge, T. A., Jackson, C. L., Shaw, J. C., Scott, B. A., \& Rich, B. L. (2007). Self- efficacy and work-related performance: The integral role of individual differences. Journal of Applied Psychology, 92(1), 107-127.

Judge, T. A., Van Vianen, A. E. M., \& De Pater, I. E. (2004). Emotional stability, core self- evaluations, 
and job outcomes: A review of the evidence and an agenda for future research. Human Performance, 17(3), 325-346.

Kristof-Brown, A. L., Zimmerman, R. D., \& Johnson, E. C. (2005). Consequences of individuals' fit at work: A meta-analysis of person-job, person-organization, and person-supervisor fit. Personnel Psychology, 58, 281-342. doi: 10.1111/j.1744-6570.2005.00672.x

Luyckx, K., Duriez, B., Klimstra, T. A., \& De Witte, H. (2010). Identity statuses in young adult employees: Prospective relations with work engagement and burnout. Journal of Vocational Behavior, 77(3), 339-349. doi: 10.1016/j.jvb.2010.06.002

May, D. R., Gilson, R. L., \& Harter, L. M. (2004). The psychological conditions of meaningfulness, safety and availability and the engagement of the human spirit at work. Journal of Occupational \& Organizational Psychology, 77(1), 11-37. doi: 10.1348/096317904322915892

Peterson, C., Park, N., Hall, N., \& Seligman, M. E. P. (2009). Zest and work. Journal of Organizational Behavior, 30(2), 161-172. doi: 10.1002/job.584

Preacher, K., \& Hayes, A. (2008). Asymptotic and resampling strategies for assessing and comparing indirect effects in multiple mediator models. Behavior Research Methods, 40(3), 879-891. doi: 10.3758/brm.40.3.879

Rigotti, T., Schyns, B., \& Mohr, G. (2008). A short version of the Occupational Self-Efficacy Scale: Structural and construct validity across five countries. Journal of Career Assessment, 16(2), 238-255. doi: 10.1177/1069072707305763

Rosso, B. D., Dekas, K. H., \& Wrzesniewski, A. (2010). On the meaning of work: A theoretical integration and review. Research in Organizational Behavior, 30(0), 91-127. doi: 10.1016/j.riob.2010.09.001

Saks, A. M., \& Ashforth, B. E. (2002). Is job search related to employment quality? It all depends on the fit. Journal of Applied Psychology, 87(4), 646-654. doi: 10.1037/0021-9010.87.4.646

Savickas, M. L., Nota, L., Rossier, J., Dauwalder, J.-P., Duarte, M. E., Guichard, J., . . v van Vianen, A. E. M. (2009). Life designing: A paradigm for career construction in the 21st century. Journal of Vocational Behavior, 75(3), 239-250. doi: 10.1016/j.jvb.2009.04.004

Schaufeli, W. B., Bakker, A. B., \& Salanova, M. (2006). The measurement of work engagement with a short questionnaire: A cross-national study. Educational and Psychological Measurement, 66(4), 701-716.

Schneider, B. (1995). The ASA framework: An update. Personnel Psychology, 48(4), 747-773.

Schuurman, D. J. (2003). Vocation: Discerning our callings in life. Grand Rapids, MI: Wm B. Eerdmans Publishing Co.

Seppälä, P., Mauno, S., Feldt, T., Hakanen, J., Kinnunen, U., Tolvanen, A., \& Schaufeli, W. (2009). The construct validity of the Utrecht Work Engagement Scale: Multisample and longitudinal evidence. Journal of Happiness Studies, 10(4), 459-481. doi: 10.1007/s10902-008-9100-y

Skorikov, V. B., \& Vondracek, F. W. (2011). Occupational identity. In S. J. Schwartz, K. Luyckx \& V. L. Vignoles (Eds.), Handbbok of identity theory and research (pp. 693-714). New York: Springer.

Steger, M. F., \& Dik, B. J. (2010). Work as meaning: Individual and organizational benefits of engaging in meaningful work. In P. A. Linley, S. Harrington \& N. Garcea (Eds.), Oxford handbook of positive psychology and work (pp. 131-142). New York, NY US: Oxford University Press.

Steger, M. F., Pickering, N. K., Shin, J. Y., \& Dik, B. J. (2010). Calling in work: Secular or sacred? Journal of Career Assessment, 18(1), 82-96. doi: 10.1177/1069072709350905

Stumpp, T., Muck, P. M., Hülsheger, U. R., Judge, T. A., \& Maier, G. W. (2010). Core self- evaluations in Germany: Validation of a German measure and its relationships with career success. Applied Psychology, 59(4), 674-700. doi: 10.1111/j.1464-0597.2010.00422.x 
Thompson, E., \& Feldman, D. B. (2010). Let your life speak: Assessing the effectiveness of a program to explore meaning, purpose, and calling with college students. Journal of Employment Counseling, 47(1), 12-19.

Vondracek, F. W. (1992). The construct of vocational identity and its use in career theory and research. Career Development Quarterly, 41(2), 130-144.

Wrzesniewski, A. (2003). Finding positive meaning in work. In K. S. Cameron, J. E. Dutton \& R. E. Quinn (Eds.), Positive organizational scholarship (pp. 296-308). San Francisco: BerrettKoehler.

Wrzesniewski, A., McCauley, C., Rozin, P., \& Schwartz, B. (1997). Jobs, careers, and callings: People's relations to their work. Journal of Research in Personality, 31(1), 21-33. doi: 10.1006/jrpe.1997.2162

Yuan, K. H., \& Bentler, P. M. (2000). Three likelihood-based methods for mean and covariance structure analysis with nonnormal missing data. In M. E. Sobel \& M. P. Becker (Eds.), Sociological Methodology 2000 (pp. 165-200). Washington, D.C.: ASA. 
Table 1

Bivariate correlations among the assessed constructs $(N=529)$

\begin{tabular}{|c|c|c|c|c|c|c|c|c|c|}
\hline & $M$ & $S D$ & 1 & 2 & 3 & 2 & 5 & $\epsilon$ & 7 \\
\hline 1. Calling & 7.12 & 1.63 & $(.81)$ & .58 & .57 & .69 & .68 & .66 & .57 \\
\hline 2. Meaningfulness & 17.33 & 3.88 & & (.90) & .39 & .36 & .69 & .63 & .41 \\
\hline 3. Identity & 27.30 & 5.94 & & & (.89) & .47 & .63 & .52 & .58 \\
\hline 4. Self-efficacy & 28.30 & 4.43 & & & & $(.87)$ & .50 & .51 & .74 \\
\hline 5. Work engagement & 44.51 & 10.66 & & & & & (.95) & .76 & .58 \\
\hline 6. P-J fit & 14.80 & 3.23 & & & & & & $(.92)$ & .60 \\
\hline 7. CSE & 46.86 & 6.84 & & & & & & & $(.85)$ \\
\hline
\end{tabular}

Note. Cronbach's alpha values are in diagonal. P-J: Person-Job. CSE: Core self-evaluations.

All correlations were significant at the $p<.001$ level. 
Table 2

Standardized indirect effects of presence of calling on work engagement trough work meaningfulness, occupational identity, and occupational self-efficacy, controlled for core self- evaluations ( $N=529$ )

\begin{tabular}{lllll}
\hline Mediator & Point estimate & SE & \multicolumn{2}{l}{ Bootstrapping BC 95\% Cl } \\
& & & Lower & Higher \\
\hline Meaningfulness & $.22^{* * *}$ & .03 & .15 & $.29^{\dagger}$ \\
Identity & $.14^{* * *}$ & .02 & .09 & $.20^{\dagger}$ \\
Self-efficacy & $.01^{*}$ & .01 & -.01 & .03 \\
Total indirect effect & $.38^{* * *}$ & .03 & .31 & $.45^{\dagger}$ \\
\hline
\end{tabular}

Note.

$* p<.05$

$* * * p<.001$

$+95 \% \mathrm{Cl}$ that does not include zero 